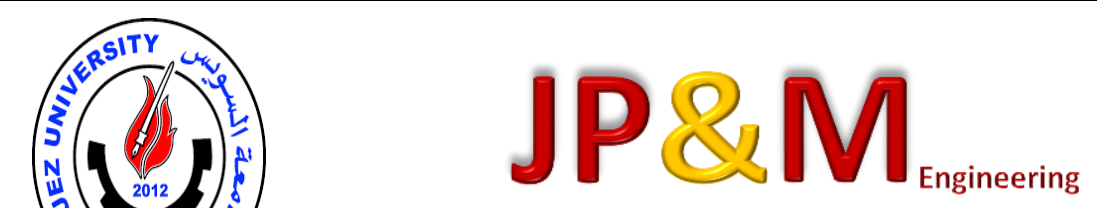

Journal of Petroleum and Mining Engineering

\title{
Weld pitch effects on friction stir welding of aluminum alloys
}

\author{
Essa, A.R.S, a,b* , Ahmed, M. M.Z. ${ }^{c, d}$, Mohamed, A. Y. A. ${ }^{\text {a }}$ \\ ${ }^{a}$ Mechanical Department, Faculty of Technology and Education, Suez University, Suez, Egypt. \\ ${ }^{b}$ Mechanical Engineering Department, Egyptian Academy for Engineering \& Advanced Technology, Affiliated to Ministry of Military \\ Production, Cairo, Egypt. \\ c Department of Mechanical Engineering, College of Engineering at Al Kharj, Prince Sattam Bin Abdulaziz University, Al Kharj 11942, Saudi \\ Arabia. \\ d Department of Metallurgical and Materials Engineering, Faculty of Petroleum and Mining Engineering, Suez University, Suez 43512, \\ Egypt. \\ *Corresponding author e-mail: ahmed.eessa@suezuniv.edu.eg (A.R.S Essa)
}

\section{Article Info}

Received 6 May 2021

Revised 24 May 2021 Accepted 30 Nov. 2021

\section{Keywords}

Weld pitch; Friction stir welding; Aluminum alloys; Mechanical properties.

\begin{abstract}
In the present work, the friction stir welding (FSW) was carried out on three aluminum alloys (AA1050-H12, AA 5754-24 and AA 7075) to investigate the effects of the weld pitch on the peak temperature and mechanical properties of the joints. The FSW was performed at different weld pitches of $0.2,0.5$, and $0.8 \mathrm{~mm} / \mathrm{rev}$. The ultimate tensile strength increased with increasing the weld pitch for the strain hardened alloys AA1050 and AA5754. A dramatic decrease of the ultimate tensile strength with increasing the weld pitch is predominant for the precipitation hardened alloy AA 7075. A maximum joint efficiency (tensile percentage) of $94 \%$ is attained for AA5754 at the higher weld pitch of $0.8 \mathrm{~mm} / \mathrm{rev}$ whereas the minimum joint efficiency of $61.4 \%$ is a share of AA $7075-T 6$ at the lower weld pitch of $0.2 \mathrm{~mm} / \mathrm{rev}$. Different hardness profiles were obtained for the investigated alloys based on the different strengthening mechanisms.
\end{abstract}

\section{Introduction}

Friction stir welding (FSW) is a solid-state joining process in which the heat required for softening of the materials produced from the conversion of mechanical energy into heat energy [1]-[14], . Nowadays, the parameters that control the generated heat are well known to be mainly the tool rotation speed, the traverse welding speed and the tool design. Numerous studies focused on these parameters individually, but only few papers discuss the important speed index which is the weld pitch [15], [16] that combine both the tool traverse speed $(\mathrm{mm} / \mathrm{min})$ and the rotation rate $(\mathrm{rpm})$. The weld pitch is the ratio between traverse welding speed (TS) and tool rotation speed (RS). The influence of both tool rotation speed and traverse welding speed on the FSW process was researched by several authors. According to Li et al [17] the heat pattern during FSW of 6061 aluminum alloy changes with increasing tool rotation speed. Also, the flow pattern changes when the tool rotation speed exceeds $900 \mathrm{rpm}$. The temperature dramatically varies with the tool rotation speed and reaches a maximum value at $900 \mathrm{rpm}$ and then the temperature falls with increasing tool rotation speed. Sunilkumar et al studied the microstructure and hardness dependence on the tool rotation speed of FSWed $9 \% \mathrm{Cr}-1 \%$ Mo steel [18]. They informed that lower values of tool rotation speed can limits the width of heat affected zone (HAZ) and thermo-mechanical affected zone (TMAZ). Moreover, the properties of dissimilar aluminum alloys FSWed joints was studied by Dinaharan et al [19] and they found that the flow pattern of the materials clearly affected by the tool rotation speed. Likewise, traverse welding speed effects on the properties of friction stir welded joints of aluminum and copper joint was researched by Muthu et al [20]. The defect free joints were produced when using traverse welding speed $(70-80 \mathrm{~mm} / \mathrm{min})$. James et al [21] notice a reduction in the strength of AA 5083 as the traverse welding speed increases from 80 to 200 $\mathrm{mm} / \mathrm{min}$.

As stated before very few researchers investigate the effect of the weld pith (WP) on the FSW. The present paper aims to investigate the effect of WP on the strength, peak temperature, and soundness of friction stir welded joints. Three different properties of aluminum alloys, namely AA1050, AA5754 and AA7075 will be used. These three aluminum alloys cover a wide range of applications such as naval applications, vehicle industry and aviation industries [22]-[29]. The macrostructure of the produced joints will be inspected to ensure the soundness. the peak 
temperature in the midpoint of the nugget zone will be measured. The tensile strength of the joints will be evaluated. Both the peak temperature and tensile properties will be plotted against the weld pitch.

\section{Experimental Work}

A cylindrical tool pin used for welding is manufactured from a $30 \mathrm{~mm}$ diameter $\mathrm{H} 13$ cold worked tool steel rod $(0.39 \% \mathrm{C}, 0.1 \% \mathrm{Si}, 0.40 \% \mathrm{Mn}$, $5.2 \% \mathrm{Cr}, 0.95 \% \mathrm{~V}, 1.4 \% \mathrm{Mo}$, and $90.6 \mathrm{wt} \% \mathrm{Fe})$, and heat-treated to $62 \mathrm{HRC}$. The tool design is prepared with a smooth $19 \mathrm{~mm}$ diameter shoulder, $2^{\circ}$ concavity, and the pin dimensions of $4.6 \mathrm{~mm}$ long and $6 \mathrm{~mm}$ diameter as shown in Fig.1.

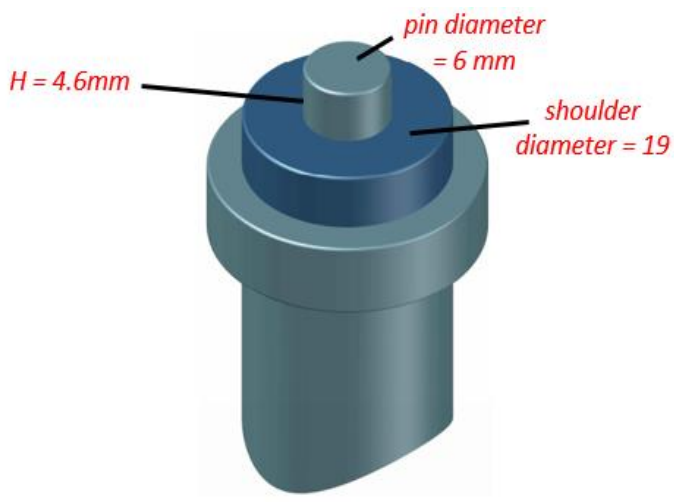

Figure $13 D$ drawing of the used FSW tool in this study.

Friction stir welding of butt joints of AA1050-H12, AA5754-H24, AA7075-O and AA7075-T6 aluminum alloys was performed using the FSW machine (for research and development at Suez University) of 22 $\mathrm{kW}$ power with max rotation speed of $3000 \mathrm{rpm}$, max welding speed of $1000 \mathrm{~mm} / \mathrm{min}$, and max vertical force of $100 \mathrm{kN}$. The chemical and mechanical properties of the studied alloys are listed in Tables 1 and 2, respectively. The solidus temperature (Ts) for AA1050, AA5754, and AA7075 aluminum alloys according to ASM are $646{ }^{\circ} \mathrm{C}, 583^{\circ} \mathrm{C}$ and $475{ }^{\circ} \mathrm{C}$, respectively [30]. The weld samples are made of two $5 \mathrm{~mm}$ thick, $100 \mathrm{~mm}$ width, and $150 \mathrm{~mm}$ long plates. Table. 3 Shows the FSW process parameters for all aluminum alloys, the tool plunge depth was $0.2 \mathrm{~mm}$ and the tool inclination of $3^{\circ}$.
Table 3 Experimental FSW conditions

\begin{tabular}{ccc}
\hline $\begin{array}{c}\text { Welding speed } \\
\text { (mm/min) }\end{array}$ & $\begin{array}{c}\text { Rotation speed } \\
\text { (rpm) }\end{array}$ & $\begin{array}{c}\text { Weld pitch } \\
\text { (mm/rev) }\end{array}$ \\
\hline 100 & 600 & 0.17 \\
300 & 600 & 0.5 \\
500 & 600 & 0.83 \\
\hline
\end{tabular}

"Quicktemp 8630-T3 device" was used to measure temperatures on the top surfaces of the joints during FSW. Macroscopic examination of the weld joint cross section was carried out after the standard metallographic preparation up to polishing of the surface and etching with $10 \mathrm{~g} \mathrm{NaOH}$ in $90 \mathrm{ml}$ distilled water to reveal the macro features. Tensile testing was carried out using $300 \mathrm{KN}$ capacity tensile testing machine (Instron 4210, Norwood, MA, USA) using an initial strain rate in the quasi-static rate $\left(\varepsilon \approx 0.001 \mathrm{~s}^{-1}\right)$. Flat tensile specimens were cut perpendicular to the welding direction (WD), the velocity of the moving head of the machine was $0.1 \mathrm{~mm} / \mathrm{s}$.

Vickers hardness testing machine (HWDV-75, TTS Unlimited, Osaka, Japan) was used to evaluate the hardness profiles along the width of the weld samples using a load of $1.0 \mathrm{~kg}$ and dwell time of $15 \mathrm{~s}$.

\section{Results and Discussions}

Figure 2 shows the different weld pitches on the top surface of the joint and indicated by dashed red lines. This is clearly indicating that the weld pitch represents the tool advance per each revolution and this on other way expresses the thickness of the layer built behind the tool to form the joint in the solid state. The weld pitch parameter expected to affect the joint properties due to its effect on the cooling rate, strain, and strain rate.

\subsection{Nugget zone shape variations depending on WP}

Figure 3 illustrates the cross-section macrostructure of FSWed AA 1050, AA 5457 and AA 7075 aluminum alloys. At first glance appears that the nugget zone size decreases with increasing WP for the three alloys. For AA 1050 the nugget zone or the stir zone take the semi spherical shape. but with increasing the WP the

Table 1 Nominal chemical composition of present aluminum alloys

\begin{tabular}{rccccccccc}
\hline \multirow{2}{*}{ Type } & \multicolumn{10}{c}{ (Elements wt.\%) } \\
\cline { 2 - 11 } & $\mathbf{S i}$ & $\mathbf{F e}$ & $\mathbf{C u}$ & $\mathbf{M n}$ & $\mathbf{M g}$ & $\mathbf{C r}$ & $\mathbf{Z n}$ & $\mathbf{T i}$ & Al \\
\hline 1050 & 0.08 & 0.27 & 0.02 & 0.01 & 0.01 & - & 0.02 & 0.02 & rest \\
5754 & 0.4 & 0.4 & 0.1 & 0.5 & $2.6-3.2$ & 0.3 & 0.2 & 0.15 & rest \\
7075 & 0.07 & 0.21 & 1.94 & 0.05 & 2.66 & 0.21 & 5.94 & 0.01 & rest \\
\hline
\end{tabular}

Table 2 Tested mechanical properties of present aluminum alloys

\begin{tabular}{rccc}
\hline Alloy & Tensile Strength (MPa) & Proof Stress 0.2\% (MPa) & Elongation (\%) \\
\hline AA1050-H12 & 103.25 & 79 & 11.43 \\
AA5754-H24 & 260.57 & 205 & 12.93 \\
AA7075-O & 237.4 & 108 & 15.6 \\
AA7075-T6 & 570 & 505 & 10
\end{tabular}


stir zone becomes narrower. The formation of semi spherical shape for AA 1050 indicates that the heat generated during FSW is enough to plasticize the stir zone. For the other two alloys (5457 and 7075) the stir zone takes a conical shape at lower value of WP but with increasing the WP the nugget zone becomes narrower and be more restricted to the pin shape. A small defect is observed in the lower part of the stir zone of AA 7075 at higher value of WP $(0.83 \mathrm{~mm} / \mathrm{rev})$ which may be attributed to the reduction of heat generated at this FSW conditions.
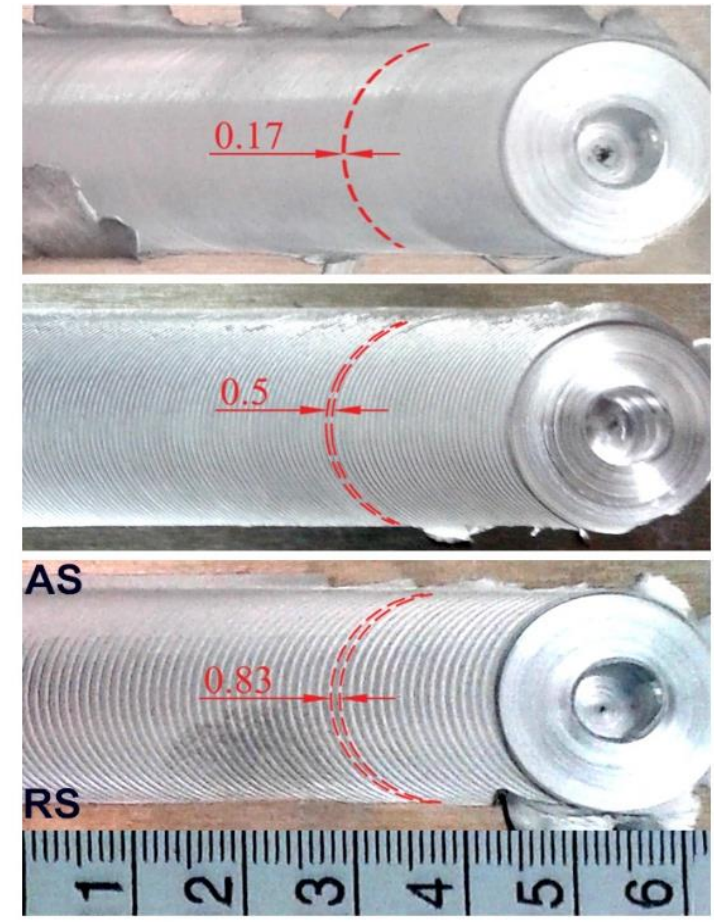

Figure 2 Top view example of friction stir welded 5754 aluminum alloy showing three values of the weld pitch $0.17 \mathrm{~mm}, 0.5 \mathrm{~mm}$ and $0.83 \mathrm{~mm}$. ("AS" means the advancing side and "RS" is the retreating side). zone (nugget) decreases with increases the WP. The reduction of the soft area (nugget zone) for this type of alloys (lower deformation resistance) may cause this slight increase of ultimate tensile strength and consequently increasing the joint efficiency (WE) [31], [32]. This result agree with the results of Hidetoshi et al [32] in that with increasing the WP the UTS increases when using a nonthreaded pin tool. The smooth pin tool gives a sounder joint than when using threaded pin. On the other hand, the weld joint efficiency (WE) for AA $1050-\mathrm{H} 12$ reaches a maximum value about $84.45 \%$ when the WP is $0.83 \mathrm{~mm}$. Liu et al [31] concluded that the WE reaches $80 \%$ of the base metal (AA 1050-H24) when they try to optimize the optimum values of WP that gives the highest WE.

\subsubsection{AA 5754-H24 - high deformation resistance alloy}

AA 5754 aluminum alloy like AA 1050 in that they are a non-heat treatable alloys and no methods can be used for improving the mechanical properties after friction stir welding [33]. The friction stir welding of the strain hardening aluminum alloys (such as AA 5754) results in a soft zone in the welded joints that accompanied by lower dislocation density in the nugget zone and cause the deterioration of the mechanical properties [31], [33]. So, access must be attempted to reach the optimum conditions for the welding of this types of aluminum alloys.

Fig 4 (b) illustrate the relation between the WP as FSW parameter on the UTS strength and consequent weld joint efficiency (WE) of the friction stir welded AA 5754 alloy. It is observed a considerable increase in the UTS and WE with increasing the WP. At WP $0.83 \mathrm{~mm}$ the UTS reach about $245 \mathrm{MPa}$ and the WE reach $94 \%$ compared with WE of nearly $90 \%$ at WP equal to $0.17 \mathrm{~mm}$. The highest value of WE obtained at WP of $0.83 \mathrm{~mm}$ may be attributed to the formation isotropic texture that formed in the stir zone after FSW [33]. Moreover, the WE range from about $90 \%$ to $94 \%$ with WP ranges from $0.17 \mathrm{~mm}$ to $0.83 \mathrm{~mm}$. Generally, the increasing of strength of the AA 5745 alloy is expected since this alloy as stated before is a stain hardening alloy. The results of the present work have a good agreement with the work of Part et al [16].

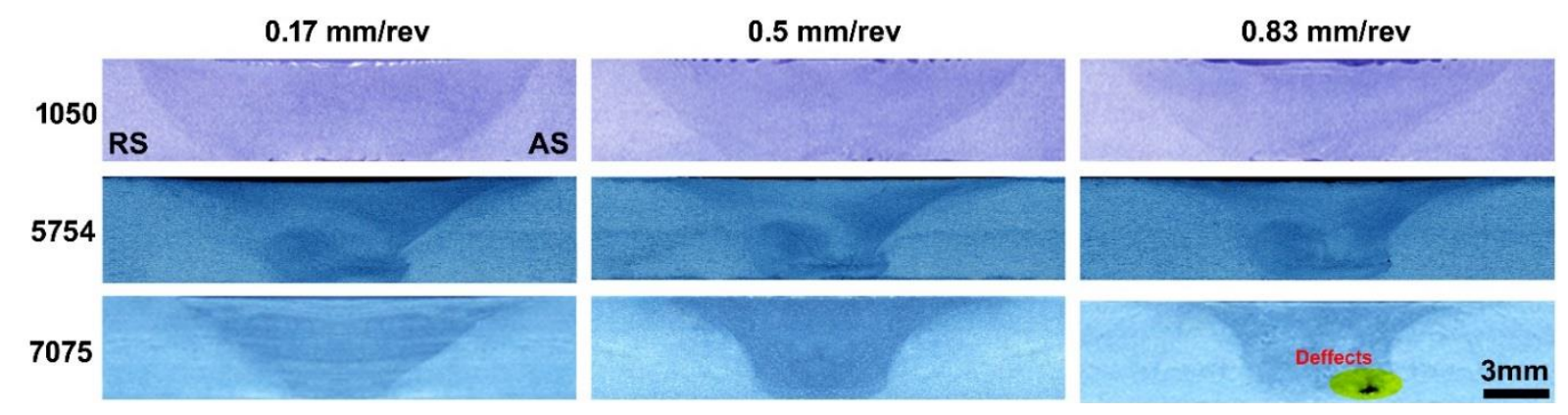

Figure 3 Optical macrographs of the transverse cross section of the different aluminum alloys FSWed joints: AA1050, AA5754 and AA7075.

\subsection{Effect of WP on the tensile strength and joint efficiency (tensile strength percent)}

\subsubsection{AA 1050-H12 aluminum alloy- a soft alloy}

Figure 4 (a) indicates that the ultimate tensile strength (UTS) of the friction stir welded AA 1050 increases slightly with increasing weld pitch. The FSW welding cause softening (lower strength) of nugget stir zone (decrease of UTS). Referring to Figure 3 which indicate that the soft

\subsubsection{AA 7075 - high strength and heat treatable alloy}

Fig $4 \mathrm{c}$ and $4 \mathrm{~d}$ show the variation of UTS and weld joint efficiency (WE) with weld pitch (WP) for the friction stir welded AA 7075-O and AA 7075-T6 respectively. An opposite behavior to the strain hardening alloy (1050 and 5754) the ultimate tensile strength and consequently the WE of the friction stir welded joints of AA 7075 in the 0 and T6 conditions decrease dramatically with increasing the WP. 

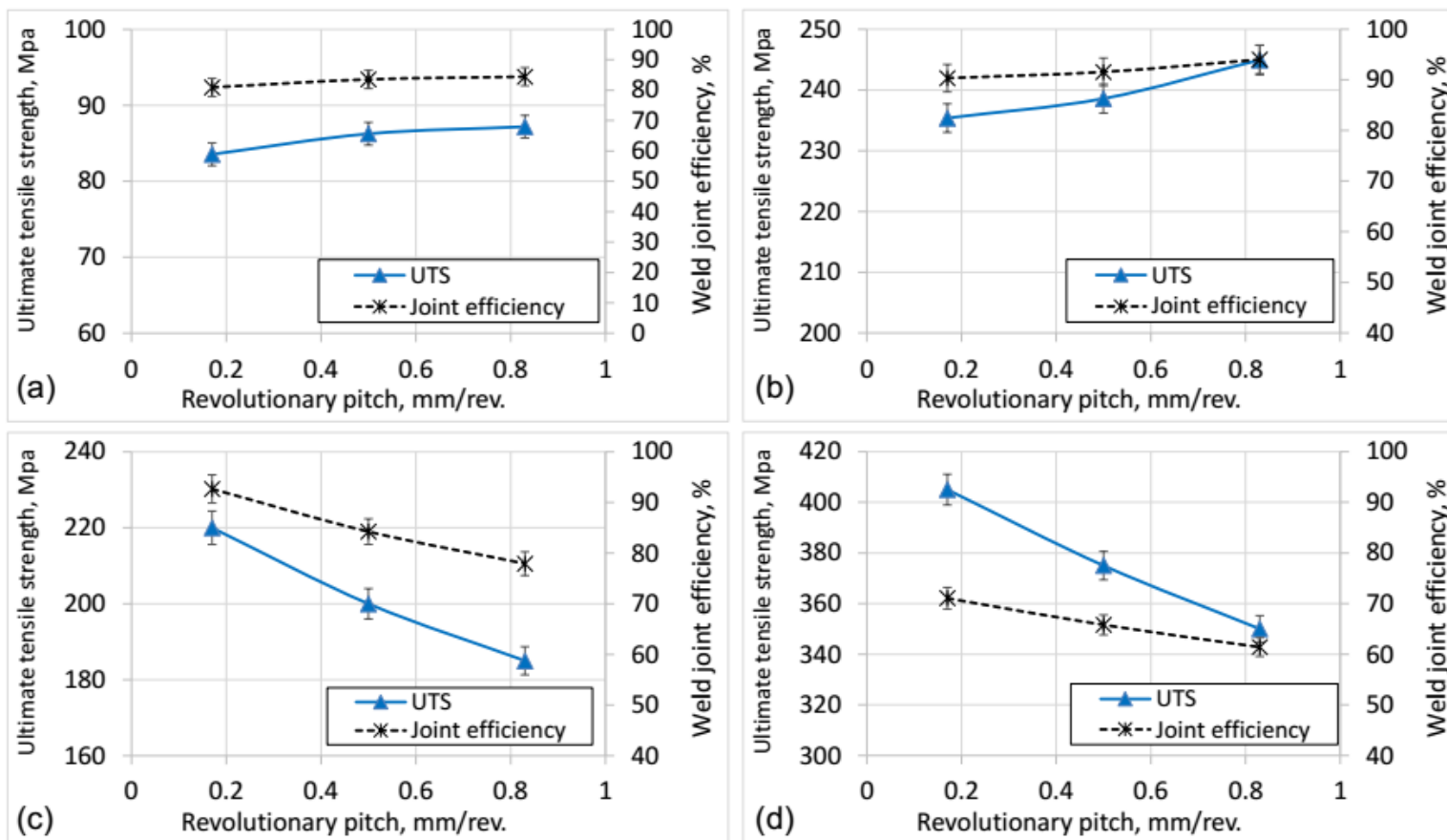

Figure 4 Ultimate tensile strength of FSW joints (a) AA1050-H12, (b) AA5754-H24, (c) AA7075-O, and (d) AA7075-T6.

For AA 7075-O alloy, the UTS decreases strongly from $220 \mathrm{MPa}$ to near $185 \mathrm{MPa}$ with increasing the WP from $0.17 \mathrm{~mm}$ to $0.83 \mathrm{~mm}$. Also, the WE decrease from nearly $92.67 \%$ at WE of 0.17 to less than $78 \%$ at WP of 0.83 . In a same manner for AA 7075-T6 the UTS decreases from nearly $405 \mathrm{MPa}$ at WP of $0.17 \mathrm{~mm}$ to about $350 \mathrm{MPa}$ at $0.83 \mathrm{~mm}$ welding pitch and the WE decrease from $71 \%$ at WP of $0.17 \mathrm{~mm}$ to $61 \%$ at $0.83 \mathrm{~mm}$ weld pitch. Generally, the heat treatable aluminum alloys (such as AA 7075) is very sensitive to heat and deformation. Moreover, it can be noticed that the aluminum alloy AA 7075-O (an annealed condition) is less sensitive to the variation of WP than the T6 temper condition. The friction stir welding of 7075 aluminum alloys produce a non-homogeneous nugget zone since the UTS in middle top part is higher than the middle bottom section [34] and this may be attributed to that the nugget zone is wider in the upper part and narrower in the lower section of the stir zone fig 3 . The increasing of WP causes a decrease in the nugget area (Fig. 3) so a reduction in the tensile strength will be expected.

\subsection{Effect of WP on Temperature}

Figure 5 illustrates the effect of weld pitch (WP) on the peak temperature in the nugget center. Also, the ratio between the maximum temperature $\left(T_{\max }\right)$ and the solidification temperature $\left(T_{s}\right)$ is plotted as $\left(T_{\max } / T_{s}\right)$ against the WP. It is noted that as the WP increase the peak temperature decreases for the three alloys (AA1050, AA5754 and AA7075) this is because the reduction of the heat input with increasing WP [31] . Also, the ratio $\left(T_{\max } / T_{s}\right)$ decreases with increasing the WP. It is observed for the strain hardening alloys (AA 1050 and AA 5754) that the peak temperature falls strongly with increasing the WP, whereas the drop of the peak temperature is small with increasing the WP for the high strength AA 7075 alloy. The solidus temperature for the AA 1050 and AA 5754 alloys are $646{ }^{\circ} \mathrm{C}, 583^{\circ} \mathrm{C}$ respectively whereas the solidus temperature for AA 7075 is $475{ }^{\circ} \mathrm{C}$ that means a high heat input is required to soften the sir zone of AA 1050 and AA 5754 alloys and a higher value of peak temperature is attained. In the case of AA 7075 (a relative lower solidification temperature) the peak temperature is lower compared with the two other alloys. So, the AA 1050 and AA 5754 alloys were more sensitive to the increase of the WP than the AA 7075 alloy.

Another important correlation is the relation between the heat input presented by (Tmax/Ts) ratio and the tensile percentage expressed as weld joint efficiency (WE) that illustrated in Fig. 6. The most important observation is that with decreasing the heat input (increasing of WP) the tensile percentage increases for both AA 1050 and AA 5754 alloys is increased. On the other hand, for AA 7075 a clear reduction of tensile percentage is observed with decreasing heat input (increasing the WP). For the two strain hardening alloys (AA 1050 and AA 5754 ) the decrease of the heat input causes the refining of grain size in the nugget zone [35]. Whereas, the drop in the tensile percentage of the heat treatable alloy AA 7075 with decreasing of heat input may be attributed to the inhomogeneity in the nugget zone and the formation of small defects as shown in Fig. 3 in the present work [34].

The hardness distribution of the cross sections of the joints welded at different weld pitches (WP) for the used aluminum alloys are illustrated in Fig 7. For AA 1050 alloy a soft region is formed in the stir zone indicated by the lower hardness values in the middle zone of the joint at all weld pitches applied Fig 7a. A slight increase of hardness with increase of the WP is observed which will agree with the work done by Liu et al [31] Also, a reduction of hardness is also observed in the hardness profile of the AA 5754 that indicates the formation of softer zone relative to the base alloy. A homogeneous distribution of hardness is also clear this may be a result of homogeneous dynamic recrystallization occur in the stir zone [33]. On the other hand, regarding the hardness profile for the AA 7075-O and AA 7075-T6 an opposite profile is observed. Many factors affecting on the hardness profile of 7075 aluminum 
alloy [36]-[38] and the same results are obtained by Ito et al [37]. and the welded material, and a relatively high cooling rates that prevent the phase precipitation [36].
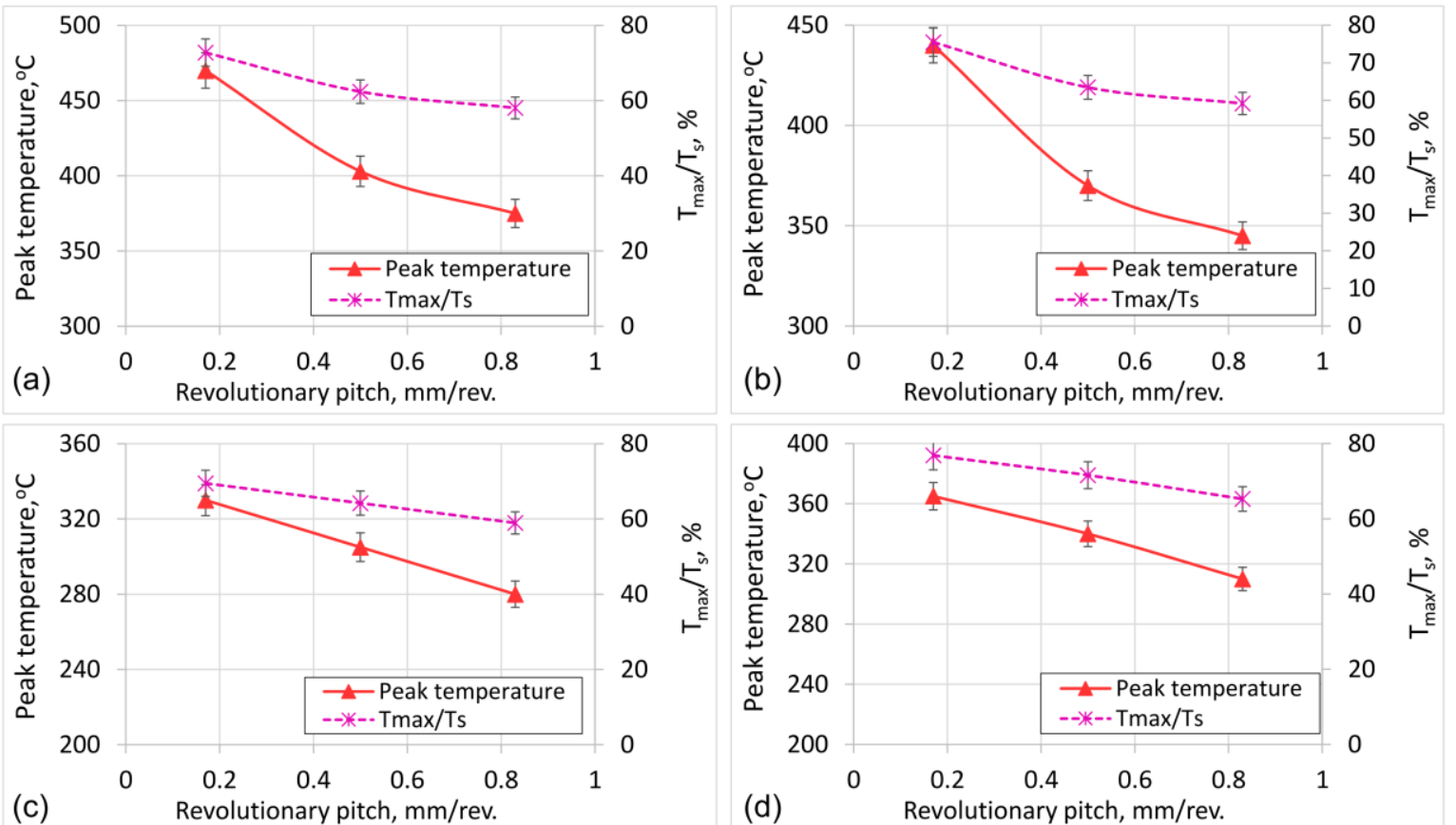

Figure 5 Peak temperature of FSW joints measured on top surface of advancing side: (a) AA1050-H12, (b) AA5754-H24, (c) AA7075-O, and (d) AA7075-T6.
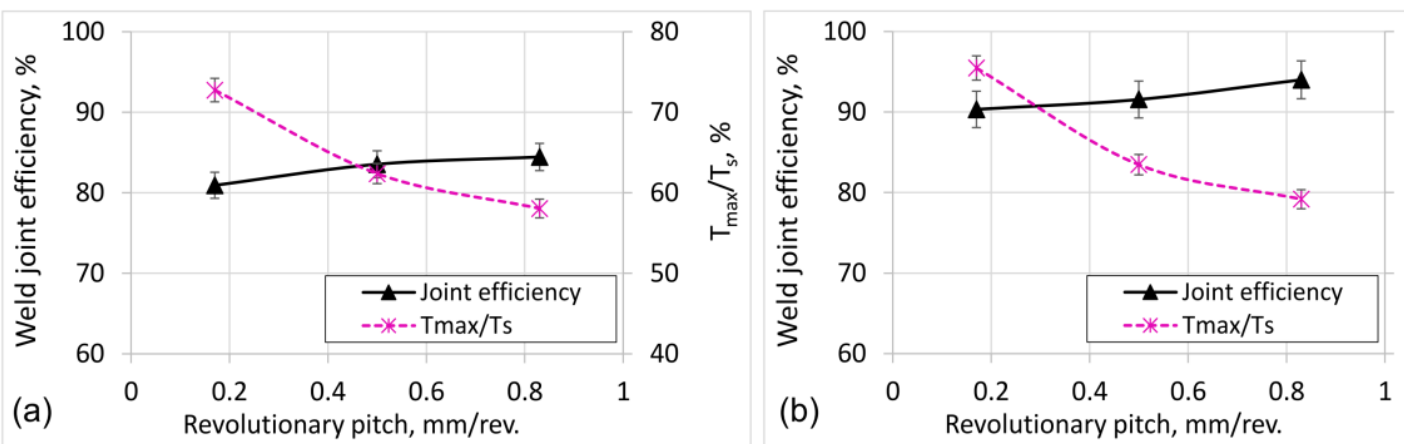

80
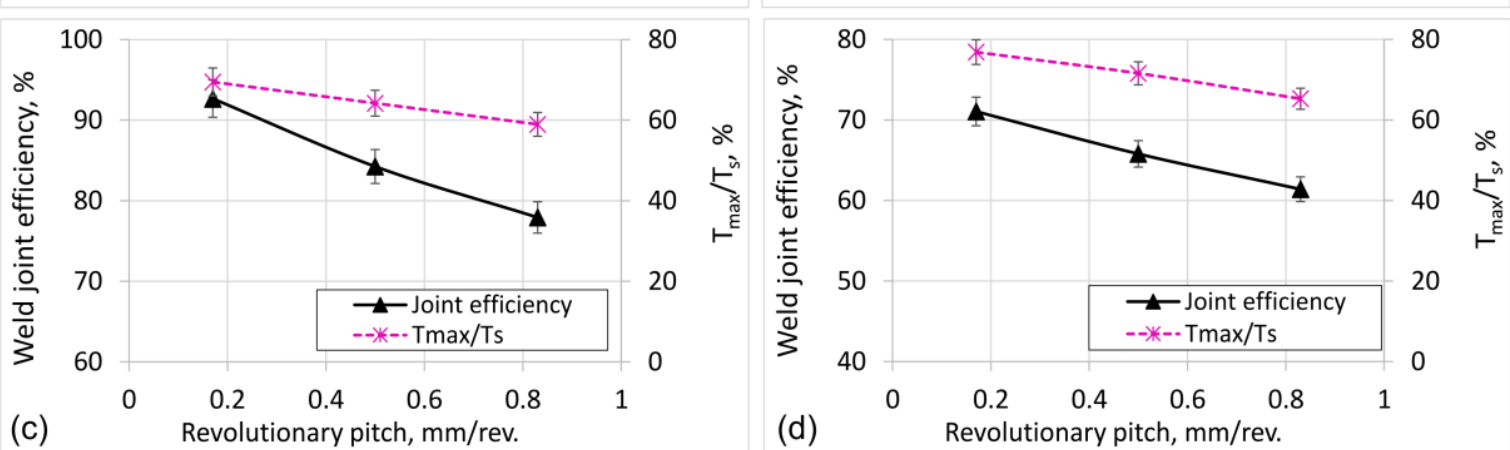

Figure 6 Effect of peak temperature ratio on weld joint efficiency of FSW joints: (a) AA1050-H12, (b) AA5754-H24, (c) AA7075-O, and (d) AA7075-T6.

They found that a fine equiaxed recrystallized was formed in the stir zone. They concluded that no anisotropy detected along the weld line. The difference in the hardness distribution between AA 7075-O and AA 7075-T6 can be discussed based on Hall-Petch relation and other strengthening mechanisms. The drop of hardness in the stir zone of AA 7075-T6 (Fig 7d) may associated with the dissolution or coarsening of the precipitates of this zone due to the heat generated by the friction of the FSW tool
On the other hand, the increase of hardness in the stir zone of AA 7075-O (Fig 7c) can be explained by the formation of fine grains the stir zone. The grain refinement may be caused by the lower heat input and higher cooling rate that prevent the chance of grain coarsening [39]. The increase of hardness with decreasing the grain size is obeyed by Hall-Petch relation [37], [39]. 

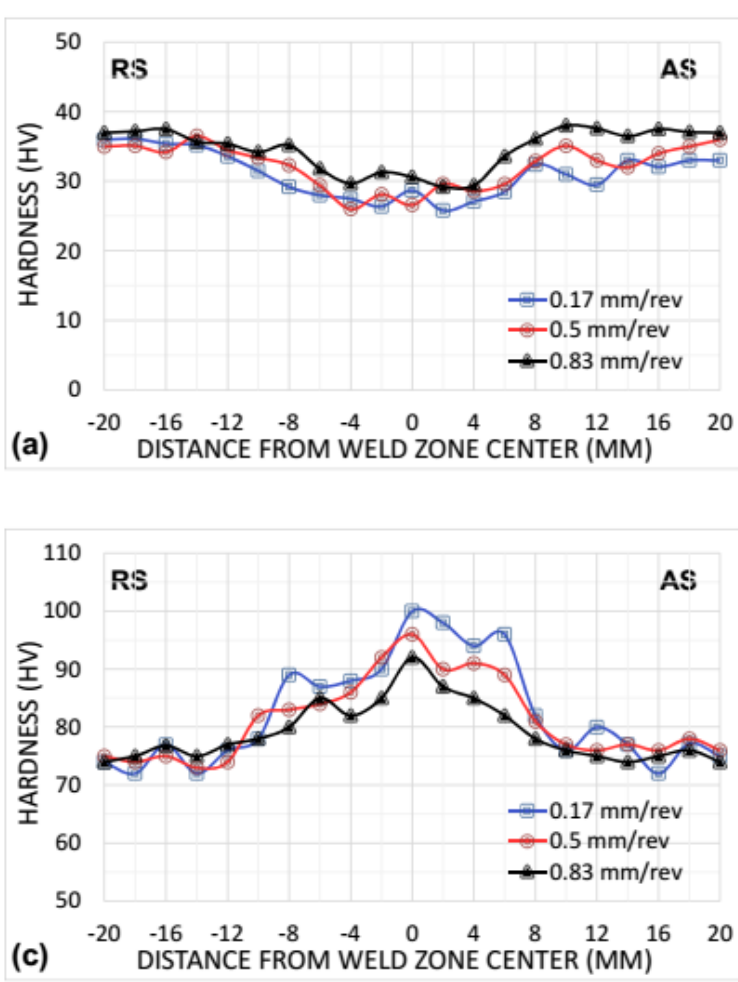
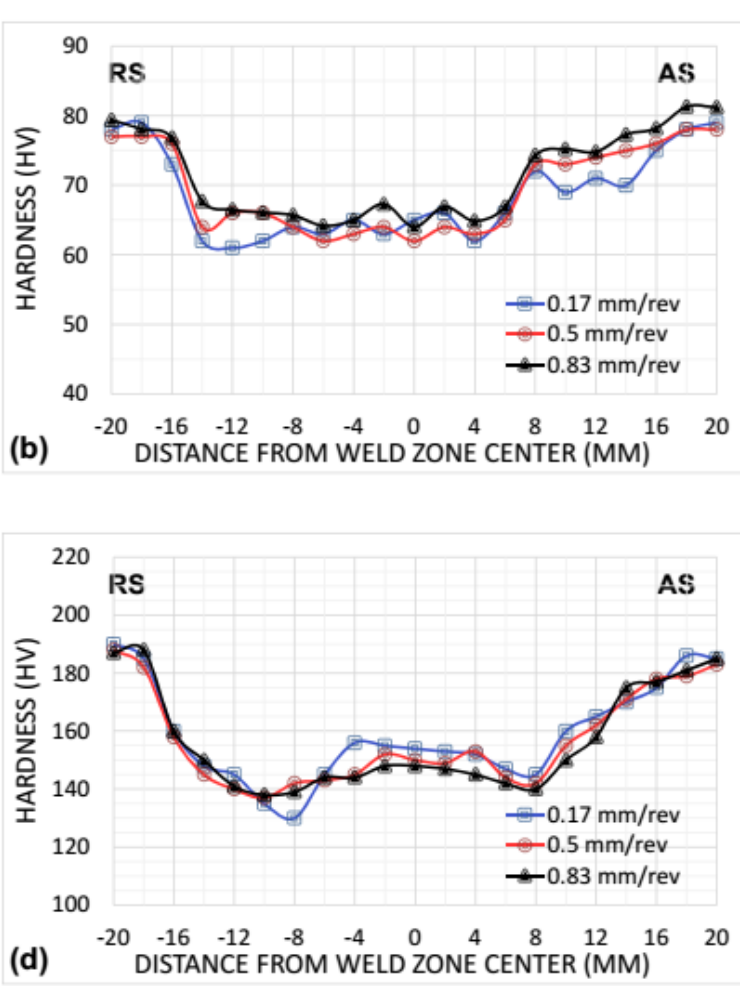

Figure 7 Vickers Hardness profiles for the cross section of FSW joints (a) AA1050-H12, (b) AA5754-H24, (c) AA7075-O, and (d) AA7075-T6.

\section{Conclusions}

In the present investigation, three aluminum alloys AA 1050-H12, AA 5754-24 and AA 7075 (O and T6 conditions) was friction stir welded at different welding parameters to investigate the effect of weld pitch (traveling speed/rotation speed) on the mechanical properties and the peak temperature of the nugget zone. From this study major conclusions can be drawn as follow:

\begin{abstract}
- A sound joints were produced for AA 1050 and AA 5754 at the three weld pitch values $(0.17,0.5$ and $0.83 \mathrm{~mm})$, whereas a small defect was observed in cross section of AA 7075 at faster weld pitch $(0.83 \mathrm{~mm})$.

- For AA 1050 and AA 5754, the ultimate tensile strength (UTS) and joint efficiency (WE) increase with increasing weld pitch (WP) whereas in the case of AA 7075 the UTS and WE were decreased with increasing of WP.

- The lower hardness values in stir zone for AA 1050 and AA 5754 is attributed the formation of soft stir zone whereas the reduction of hardness for AA 7075-T6 is caused by the coarsening and dissolution of the precipitates. Moreover, increasing the hardness of the stir zone for AA 7075-O may be caused by grain refining effect.
\end{abstract}

\section{ACKNOWLEDGEMENTS}

This research did not receive any specific grant from funding agencies in the public, commercial, or not-for-profit sectors.

\section{References}

[1] M. M. Z. Ahmed, M. I. A. Habba, N. Jouini, and B. Alzahrani, "Bobbin Tool Friction Stir Welding of Aluminum Using Different Tool Pin Geometries: Mathematical Models for the Heat Generation," pp. 1-19, 2021.
[2] M. Mohamed, Z. Ahmed, S. Ataya, M. M. E. Seleman, and T. Allam, "Grain Structure, Crystallographic Texture, and Hardening Behavior of Dissimilar Friction Stir Welded AA5083-O and," Metals (Basel)., vol. 11, pp. 1-17, 2021.

[3] A. Ramadan, S. Essa, M. Mohamed, Z. Ahmed, A. Y. Ahmed, and A. E. El-nikhaily, "An analytical model of heat generation for," J. Mater. Res. Technol., vol. 5, no. 3, pp. 234-240, 2016, doi: 10.1016/j.jmrt.2015.11.009.

[4] A. S. Hamada et al., "The microstructural evolution of friction stir welded AA6082-T6 alu- minum alloy during cyclic deformation," Mater. Sci. Eng. A, vol. 642, pp. 366-376, 2015, doi: 10.1016/j.msea.2015.06.100.

[5] H. A. El-hafez, M. M. Z. Ahmed, and E. Ahmed, "The Effect of Tool Geometry on the Microstructure and Mechanical Properties of Friction Stir Processed MIG-Welded," vol. 15, no. 4, pp. 45-55, 2018, doi: 10.9790/1684-1504024555.

[6] M. M. Z. Ahmed, M. M. E. Seleman, Z. A. Zidan, R. M. Ramadan, S. Ataya, and N. A. Alsaleh, "Microstructure and Mechanical Properties of Dissimilar Friction Stir Welded AA2024-T4 / AA7075-T6 T-Butt Joints," Metals (Basel)., vol. 11, no. $1, \quad$ p. 128,2021 , doi: https://doi.org/10.3390/met11010128.

[7] M. M. Z. Ahmed, A. Elnaml, M. Shazly, and M. M. E. Seleman, "The Effect of Top Surface Lubrication on the Friction Stir Welding of Polycarbonate Sheets," Intern. Polym. Process., pp. 1-9, 2021, doi: DOI 10.1515/ipp-2020-3991.

[8] M. M. Z. Ahmed, S. Ataya, M. M. E. Seleman, A. M. A. Mahdy, N. A. Alsaleh, and E. Ahmed, "Heat Input and Mechanical Properties Investigation of Friction Stir 
Welded AA5083/AA5754 and AA5083/AA7020," Metals (Basel)., vol. 11, no. 1, pp. 1-20, 2021, doi: DOI:10.3390/met11010068.

[9] M. M. Z. M. Z. Ahmed, M. M. El-Sayed Seleman, M. Shazly, M. M. Attallah, E. Ahmed, and E. Attallah, Moataz M. Ahmed, "Microstructural Development and Mechanical Propertiesof Friction Stir Welded Ferritic Stainless Steel AISI 40," J. Mater. Eng. Perform., vol. 28, no. 10, pp. 6391-6406, 2019, doi: https://doi.org/10.1007/s11665-019-04365-9.

[10] M. Z. Ahmed, B. P. Wynne, W. M. Rainforth, and J. P. Martin, "Crystallographic Texture Investigation of Thick Section Friction Stir Welded AA6082 and AA5083 Using EBSD," Key Eng. Mater., 2018, doi: 10.4028/www.scientific.net/KEM.786.44.

[11] M. M. Z. Ahmed, B. P. Wynne, W. M. Rainforth, A. Addison, J. P. Martin, and P. L. Threadgill, "Effect of Tool Geometry and Heat Input on the Hardness, Grain Structure, and Crystallographic Texture of Thick-Section Friction Stir-Welded Aluminium," Metall. Mater. Trans. A Phys. Metall. Mater. Sci., vol. 50, no. 1, pp. 271-284, 2019, doi: 10.1007/s11661018-4996-2.

[12] H. A.-E. Reham Reda, Mohamed Saad, Mohamed Zaky Ahmed and F. Authors, "Monitoring joint quality: Taguchi approach and structure investigation," J. Eng. Des. Technol., vol. 16, no. 2, pp. 211-232, 2018, doi: 10.1108/JEDT-10-20170108.

[13] W. Hoziefa et al., "Influence of friction stir processing on the microstructure and mechanical properties of a compocast AA2024-Al2O3 nanocomposite," Mater. Des., vol. 106, pp. 273-284, 2016, doi: 10.1016/j.matdes.2016.05.114.

[14] M. M. Z. Ahmed, E. Ahmed, A. S. Hamada, S. A. Khodir, M. M. El-Sayed Seleman, and B. P. Wynne, "Microstructure and mechanical properties evolution of friction stir spot welded high-Mn twinning-induced plasticity steel," Mater. Des., vol. 91, 2016, doi: 10.1016/j.matdes.2015.12.001.

[15] R. Crawford, G. E. Cook, A. M. Strauss, D. A. Hartman, and M. A. Stremler, "Experimental defect analysis and force prediction simulation of high weld pitch friction stir welding," Sci. Technol. Weld. Join., vol. 11 no. 6, pp. 657-665, 2006, doi: 10.1179/174329306X147742.

[16] S. W. Park, T. J. Yoon, and C. Y. Kang, "Effects of the shoulder diameter and weld pitch on the tensile shear load in friction-stir welding of AA6111/AA5023 aluminum alloys," J. Mater. Process. Technol., vol. 241, pp. 112-119, 2017, doi: 10.1016/j.jmatprotec.2016.11.007.

[17] X. Li, J. Li, F. Jin, J. Xiong, and F. Zhang, "Effect of rotation speed on friction behavior of rotary friction welding of AA6061-T6 aluminum alloy," Weld. World, vol. 62, no. 5, pp. 923-930, 2018, doi: 10.1007/s40194-018-0601-y.

[18] D. Sunilkumar, S. Muthukumaran, M. Vasudevan, S. Paneer Selvi, and M. G. Reddy, "Effect of Tool Rotation Speed on Microstructure and Hardness of Friction-Stir-Welded 9Cr-1Mo Steel," Trans. Indian Inst. Met., vol. 72, no. 6, pp. 1537-1540, 2019, doi: 10.1007/s12666-019-01621-3.
[19] I. Dinaharan, K. Kalaiselvan, S. J. Vijay, and P. Raja, "Effect of material location and tool rotational speed on microstructure and tensile strength of dissimilar friction stir welded aluminum alloys," Arch. Civ. Mech. Eng., vol. 12, no. 4, pp. 446-454, 2012, doi: 10.1016/j.acme.2012.08.002.

[20] M. F. X. Muthu and V. Jayabalan, "Tool travel speed effects on the microstructure of friction stir welded aluminum-copper joints," J. Mater. Process. Technol., vol. 217, pp. 105-113, 2015, doi: 10.1016/j.jmatprotec.2014.11.007.

[21] M. N. James, D. G. Hattingh, and G. R. Bradley, "Weld tool travel speed effects on fatigue life of friction stir welds in 5083 aluminium," Int. J. Fatigue, vol. 25 , no. 12 , pp. 1389-1398, 2003, doi: 10.1016/S0142-1123(03)00061-6.

[22] P. Prakash, R. S. Anand, and S. K. Jha, "Prediction of weld zone shape with effect of tool pin profile in friction stir welding process," J. Mech. Sci. Technol., vol. 34, no. 1, pp. 279-287, 2020, doi: 10.1007/s12206-019-1229-6.

[23] P. Rajkumar and C. Ahilan, "Effect of friction stir welding (FSW) process parameters on dissimilar aluminium alloys: An overview," AIP Conf. Proc., vol. 2283, no. October, 2020, doi: 10.1063/5.0029176.

[24] V. Msomi, N. Mbana, and S. Mabuwa, "Microstructural analysis of the friction stir welded 1050-H14 and 5083-H111 aluminium alloys," Mater. Today Proc., vol. 26, no. xxxx, pp. 189-192, 2019, doi: 10.1016/j.matpr.2019.10.038.

[25] Y. Qiao, H. Zhang, L. Zhao, and Q. Feng, "Fatigue Crack Growth Properties of AA 5754 Aluminum Alloy Gas Tungsten Arc Welding and Friction Stir Welding Joints," J. Mater. Eng. Perform., vol. 29, no. 4, pp. 2113-2124, 2020, doi: 10.1007/s11665020-04739-4.

[26] I. Kalemba-Rec, C. Hamilton, M. Kopyściański, D. Miara, and K. Krasnowski, "Microstructure and Mechanical Properties of Friction Stir Welded 5083 and 7075 Aluminum Alloys," J. Mater. Eng. Perform., vol. 26, no. 3, pp. 1032-1043, 2017, doi: 10.1007/s11665-017-2543-8.

[27] P. H. Shah and V. Badheka, "Effect of Various Welding Parameters on Corrosion Behavior of Friction-Stir-Welded AA 7075-T651 Alloys," Metallogr. Microstruct. Anal., vol. 7, no. 3, pp. 308320, 2018, doi: 10.1007/s13632-018-0440-7.

[28] M. Bevilacqua, F. E. Ciarapica, A. D’Orazio, A. Forcellese, and M. Simoncini, "Sustainability Analysis of Friction Stir Welding of AA5754 Sheets," Procedia CIRP, vol. 62, pp. 529-534, 2017, doi: 10.1016/j.procir.2016.06.081.

[29] F. Gabrielli, A. Forcellese, M. El Mehtedi, and M. Simoncini, "Mechanical Properties and Formability of Cold Rolled Friction Stir Welded Sheets in AA5754 for Automotive Applications," Procedia Eng., vol. 183, no. December, pp. 245-250, 2017, doi: $10.1016 /$ j.proeng.2017.04.030.

[30] ASM International, "properties and selection of nonferrous alloys and special-purpose materials", vol. 2, 1990. 
[31] H. J. Liu, H. Fujii, M. Maeda, and K. Nogi, “Mechanical properties of friction stir welded joints of 1050-H24 aluminium alloy," Sci. Technol. Weld. Join., vol. 8, no. 6, pp. 450-454, 2003, doi: 10.1179/136217103225005598.

[32] Hidetoshi, L. Cui, M. Maeda, and K. Nogi, "Effect of tool shape on mechanical properties and microstructure of friction stir welded aluminum alloys," Mater. Sci. Eng. A, vol. 419, no. 1-2, pp. 2531, 2006, doi: 10.1016/j.msea.2005.11.045.

[33] H. Jin, S. Saimoto, M. Ball, and P. L. Threadgill, "Characterisation of microstructure and texture in friction stir welded joints of 5754 and 5182 aluminium alloy sheets," Mater. Sci. Technol., vol. 17, no. 12, pp. 1605-1614, 2001, doi: 10.1179/026708301101509674.

[34] Y. Mao, L. Ke, Y. Chen, F. Liu, and L. Xing, "nugget of friction stir welded thick 7075 aluminum alloy joints," J. Mater. Sci. Technol., 2017, doi: 10.1016/j.jmst.2017.11.039.

[35] T. Hirata et al., "Influence of friction stir welding parameters on grain size and formability in 5083 aluminum alloy," Mater. Sci. Eng. A, vol. 456, no. 1-
2, pp. 344-349, 2007, doi: 10.1016/j.msea.2006.12.079.

[36] A. Azadi Chegeni and P. Kapranos, "A microstructural evaluation of friction stir welded 7075 aluminum rolled plate heat treated to the semi-solid state," Metals (Basel)., vol. 8, no. 1, 2018, doi: 10.3390/met8010041.

[37] T. Ito et al., "Metallurgical factors affection Vickers hardness of friction stir welded joint of 7075 aluminum alloy," Keikinzoku/Journal Japan Inst. Light Met., vol. 60, no. 6, pp. 275-281, 2010, doi: 10.2464/jilm.60.275.

[38] J. Q. Su, T. W. Nelson, R. Mishra, and M. Mahoney, "Microstructural investigation of friction stir welded 7050-T651 aluminium," Acta Mater., vol. 51, no. 3, pp. 713-729, Feb. 2003, doi: 10.1016/S13596454(02)00449-4.

[39] A. Kumar, S. K. Sharma, K. Pal, and S. Mula, "Effect of Process Parameters on Microstructural Evolution, Mechanical Properties and Corrosion Behavior of Friction Stir Processed Al 7075 Alloy," J. Mater. Eng. Perform., vol. 26, no. 3, pp. 1122-1134, 2017, doi: 10.1007/s11665-017-2572-3. 